\title{
TREE-RING RECONSTRUCTION OF JUNE-JULY MEAN TEMPERATURES IN THE NORTHERN DAXING'AN MOUNTAINS, CHINA
}

\author{
YANGAO JIANG ${ }^{1,3}$, YU WANG ${ }^{1,6}$, JUNHUI ZHANG $^{3}$, SHIJIE HAN ${ }^{2,3}$, CASSIUS E.O. COOMBS $^{4}$, \\ MARICELY ESCOBEDO ${ }^{4}$, JUNWEI WANG $^{1}$, XIAOGUANG WANG ${ }^{5}$, LIN HAO ${ }^{1,6}$, ,UODE LI $^{1}$, \\ YIJIANG TONG ${ }^{7}$, YUE GU ${ }^{3}$, SHENGZHONG DONG ${ }^{1}$, HAISHENG HE ${ }^{1}$ and JINGYU YANG ${ }^{1}$ \\ ${ }^{1}$ Experimental Teaching Center, Shenyang Normal University, Shenyang 110034, China \\ ${ }^{2}$ Shool of Life Sciences, Henan University, Kaifeng 475004, China \\ ${ }^{3}$ Institute of Applied Ecology, Chinese Academy of Sciences, Shenyang 110016, China \\ ${ }^{4}$ Centre for Carbon, Water and Food, School of Life and Environmental Sciences, University of Sydney, Camden NSW 2570. Australia \\ ${ }^{5}$ College of Environmental and Resource Sciences, Dalian Minzu University, Dalian 116600, China \\ ${ }^{6}$ College of Life Sciences, Shenyang Normal University, Shenyang 110034, China \\ ${ }^{7}$ College of food, Shenyang Normal University, Shenyang 110034, China
}

\begin{abstract}
In this study, the mean temperature of June to July was reconstructed for the period of 1880 to 2014 by using the Larix gmelinii tree-ring width data for the Mangui region in the northern Daxing'an Mountains, China. The reconstruction accounts for $43.6 \%$ of the variance in the temperature observed from AD 1959-2014. During the last 134 years, there were 17 warm years and 17 cold years, which accounted for $12.7 \%$ of the total reconstruction years, respectively. Cold episodes occurred throughout $1887-1898$ (average value is $14.2^{\circ} \mathrm{C}$ ), while warm episodes occurred during 1994$2014\left(15.9^{\circ} \mathrm{C}\right)$. Based on this regional study, the warmer events coincided with dry periods and the colder events were consistent with wet conditions. The spatial correlation analyses between the reconstructed series and gridded temperature data revealed that the regional climatic variations were well captured by this study and the reconstruction represented a regional temperature signal for the northern Daxing'an Mountains. In addition, Multi-taper method spectral analysis revealed the existence of significant periodicities in our reconstruction. Significant spectral peaks were found at 29.7, 10.9, 2.5, and 2.2 years. The significant spatial correlations between our temperature reconstruction and the El Niño-Southern Oscillation (ENSO), Pacific Decadal Oscillation (PDO) and Solar activity suggested that the temperature in the Daxing'an Mountains area indicated both local-regional climate signals and global-scale climate changes.
\end{abstract}

Keywords: Larix gmelinii, Tree rings, temperature reconstruction, El Niño-Southern Oscillation, Pacific Decadal Oscillation, Solar activity.

Corresponding authors: J. Zhang and S. Han

e-mails: jhzhang@iae.ac.cn; hansj@iae.ac.cn 


\section{INTRODUCTION}

The rise in global temperatures since the $20^{\text {th }}$ century has a significant impact on human activities (Esper et al., 2002; Moberg et al., 2005; IPCC, 2014), resulting in temperature changes at both local-regional and global scales, with a strong influence on upland as well as hydrophytic ecosystems (Cao and Woodward, 1998; Shaver et al., 2000). Warming is expected to have significant effects on ecosystems at high latitudes, where plant growth is mainly limited by temperature (Kittel et al., 2000). The Daxing'an Mountains (DM), which are ranging in the northeast across 200-300 km from east to west and extend over $1220 \mathrm{~km}$ from south to north, are one of the most sensitive areas to temperature variation of China (Ding et al., 1994; Wang et al., 1998; Zhang et al., 2016). Previous studies showed that temperature change in this region was linked with solar activities and global land-sea atmospheric circulation. The temperature will rise or fall with the intensity or weakness of solar activity (e.g. the warm period in Middle Ages and the cold period in "Little Ice Age") (Lean and Rind, 1999; Bond et al., 2001; Herrera et al., 2015).

In recent years, the temperature in northeast China has gradually increased, and the temperature in the growing season has risen significantly (Li and Gong, 2006). To understand the potential impacts of climate variation in this region, it is necessary to thoroughly understand the long-term changes and trends of climate over the last hundred years (Esper et al., 2002; Zhang et al., 2003). However, the historical and instrumental meteorological records are very limited before the 1950s. This poses the most significant impediment to comprehending the processes and mechanisms of past climatic fluctuations in this region (Bao et al., 2012). Thus, understanding the characteristics of long-term paleoclimate records are of great research value for the Daxing'an Mountains, which is fundamental for the prediction of future climate.

Over the past few years, the dendrochronological research has made significant progress in China, such as dendroecological research by Song et al., 2011, Yu et al., 2018; dendrogeomorphological research by Malik et al., 2013, 2017. Besides, because the tree-rings are highresolution climate proxies containing rich climatic information, from which long paleoclimatic records can develop (Shao et al., 2010). This method has been used to extend limited meteorological data and predicts the impacts of various factors over time in various locations around the world (Pederson et al., 2001; Mann et al., 2009; Cook et al., 2010; Davi et al., 2010; Bao et al., 2012; PAGES 2k Consortium, 2013; Pathi et al., 2017). In recent years, some climate reconstruction projects based on tree rings have also been carried out in the northern Greater Khingan Mountains (Liu et al., 2009; Zhang et al., 2011, 2013; Chen et al., 2012; Yu et al., 2012). However, to date, temperature reconstruction based on tree-ring records were still insufficient in the northern Greater Khingan Mountains (Zhang et al., 2013). Thus, this lack must be addressed. Mangui (the site codes MG) is situated in the northern Daxing'an Mountains. A large area of natural temperate old-growth forests in this location provides an excellent opportunity for the study of dendroclimatology, which will allow us to better understand the historical and current climate changes in the northern Daxing'an Mountains region.

This paper uses tree-ring data for Larix gmelinii in Mangui to (1) reconstruct and investigate temperature variability since AD 1880 based on the tree-ring widths from MG, and (2) explore the potential linkages between the reconstructed June-July temperature data and large scale climatic change.

\section{MATERIALS AND METHODS}

\section{Study area and sample collection}

Our study area is located in Mangui in the northern Daxing'an Mountains, Inner Mongolia Autonomous Region, China (Fig. 1). The region experiences a temperate continental monsoon climate, which is characterized by a long and cold winter, windy and dry spring, short and rainy summer, and cool and frosty autumn (Wu et al., 2004). The average annual temperature is $-5.7^{\circ} \mathrm{C}$, and the annual total precipitation varies from $320 \mathrm{~mm}$ to $690 \mathrm{~mm}$, the growing season is from May to September. The slope of the sample site, MG $\left(890 \mathrm{~m}\right.$ a.s. $1,52^{\circ} 12^{\prime} \mathrm{N}$ and

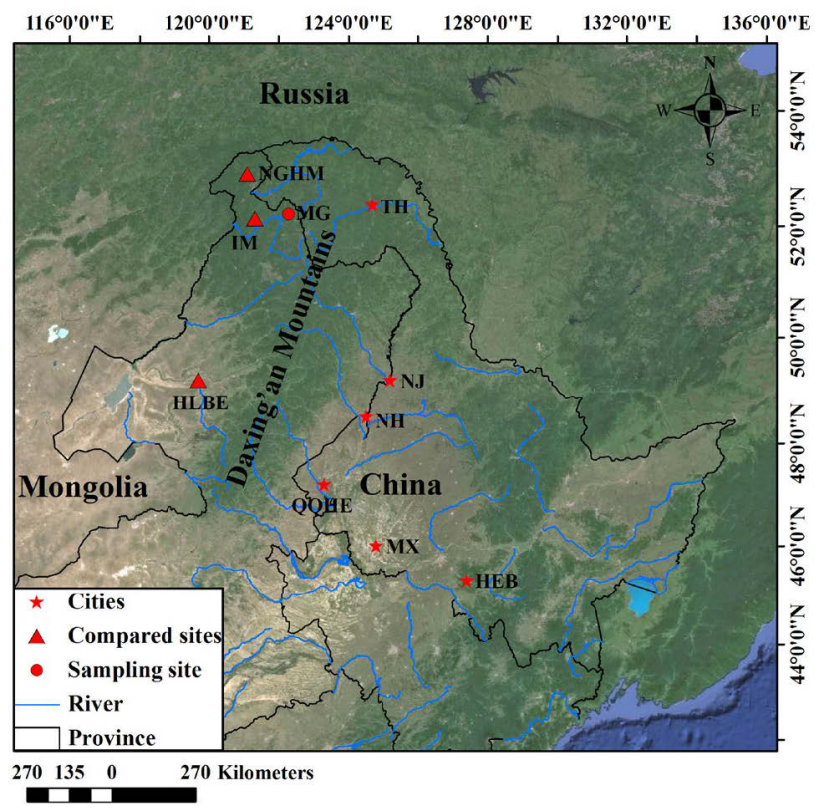

Fig. 1. Location of the sampling site (MG). Northern Greater Higgnan Mountains (HGHM) (Zhang et al., 2013), Inner Mongolia (IM) (Zhang et al., 2011) and Hulunbuir (HLBE) (Shi et al., 2015) were $u$ asterisk sed for comparison. The cities TH(Tahe), NJ (Nenjiang), NH(Nehe), QQHE(Qiqihar), MX(Maoxing) and HEB (Haerbin) were marked with asterisk. 
$122^{\circ} 17^{\prime} \mathrm{E}$ ), was from $5^{\circ}$ to $10^{\circ}$, and the aspect was south. To minimize non-climatic influences on tree growth, the selected stands of Larix gmelinii were naturally established, only healthy Larix gmelinii with no evidence of recent fire, or human disturbance were selected for sampling at breast height. To collect samples that contained consistent climate signals, the elevations difference between the trees of the sample site was within $40 \mathrm{~m}$. One or two tree-ring increment cores were extracted in NorthSouth directions from each tree (In general, two tree cores were taken in each tree, but in some cases, the collected tree core was damaged and discarded, so only one tree core was utilized). In total, 42 cores from 26 Larix gmelinii trees were collected from MG in October 2014.

\section{Development of ring-width chronologies}

All cores were preprocessed, air-dried, mounted on the wooden holders using conventional dendrochronological techniques, and subsequently were carefully polished with successively finer grit sandpaper in the laboratory (Fritts, 1976; Holmes, 1983; Cook, 1985). The tree rings were all visually cross-dated with a binocular microscope, annual ring widths were subsequently carefully measured to the nearest $0.001 \mathrm{~mm}$ by using a Velmex measuring system. The quality control of cross-dating and measurements was checked by using the COFECHA programme (Holmes, 1983). Each individual ring-width series were detrended in order to remove age-related, non-climatic growth trends (Frits, 1976). A negative exponential curve or straight line was applied to preserve as much low-frequency signal as possible (Cook, 1990). In a few cases, a cubic spline with $67 \%$ of the series length was employed when anomalous low-frequency growth trends occurred. The detrended data from individual tree cores were combined into the site chronology by using a bi-weight robust mean method to minimize the influence of extreme values, outliers or bias in tree-ring indices (Cook, 1990). Three kinds of chronologies were generated from ARSTAN: residual (RES), autoregressive (ARS) and standard (STD). The STD chronology was used for further analyses because it includes both lowand high-frequency signals. We limited our analyses to the period with an EPS of at least 0.85 to determine the length of credible chronology (Cook and Briffa, 1990; Wigley et al., 1984).

\section{Climate data}

There is no weather station near the sample sites. As such, the interpolated values, based on records from randomly selected 120 of 164 meteorological stations, were used for growth-climate response analysis. (120 weather stations in northeast China were from Chinese Meteorological Data Sharing Service System (http://cdc.cma.gov.cn), another 44 weather stations in Russia from Global Historical Climatology Network (https://www.ncdc.noaa.gov). Meteorological records from a large number of different stations, can reduce the random components or small-scale noise and enhance the reliability of statistical relationships between tree-ring widths and climate data (Pederson et al., 2001).

This interpolation method begins by fitting a partial thin-plate smoothing spline model, that is based on relating location and elevation to ground-based observations to estimate a trend surface, and then a simple kriging procedure was employed to the residuals for trend surface correction (Huang et al., 2013; Li et al., 2014). Analysis of regression was conducted between measured and interpolated precipitations and temperatures at the remaining 44 weather stations, to assess the reliability of the interpolated values. There was a high correlation with $\mathrm{R}^{2}=0.99$.

Correlation coefficients between tree-ring width indices and climatic variables from 1959 to 2014 were analyzed by using the data of monthly mean temperature and precipitation. Four climate variables were applied for the dendroclimatological analyses, including monthly total precipitation (Prec), monthly maximum temperature $\left(\mathrm{T}_{\max }\right)$, monthly mean temperature $\left(\mathrm{T}_{\text {mean }}\right)$ and monthly minimum temperature $\left(\mathrm{T}_{\min }\right)$. The climate data from the previous June to the current September was used for the correlation analysis.

Global-scale climate variables such as El NiñoSouthern Oscillation index (ENSO) and the Pacific Decadal Oscillation index (PDO) (http://climexp.knmi.nl) were also used to assess the tree-ring based climatic signals.

\section{Statistical analyses}

Pearson correlation function and growth-climate response analyses (Blasing et al., 1984; Biondi and Waikul, 2004) were utilized to identify the most accepted model for the climatic reconstruction. Subsequently, a simple linear regression equation between the tree-ring width and the climate variables was computed for the calibrated period of 1959-2014. The parameters for calibration and verification included the Pearson's correlation coefficient $(\mathrm{r})$, explained variance $\left(\mathrm{r}^{2}\right)$, reduction of error $(\mathrm{RE})$, coefficient of efficiency (CE), sign test (ST) and product means test (PMT). All statistical analyses were performed by using commercial software, SPSS12.0 (SPSS, Inc., Chicago, IL, USA).

Power spectral analysis was applied to identify reasonable periodicities and performed over the full range of the reconstruction. The spectral properties of the reconstruction series were assessed by using a multi-taper method. In addition, Spatial correlations between the reconstructed $\mathrm{T}_{\text {mean6-7 }}$ and the CRU TS 4.01 gridded $\mathrm{T}_{\text {mean }}$ dataset $\left(45-52^{\circ} \mathrm{N}, 118-127^{\circ} \mathrm{E}\right)$ during the common period of 1960-2013 were analyzed by using the KNMI climate explorer (http://climexp.knmi.nl). This was done to evaluate the spatiotemporal representativeness of the reconstruction. 


\section{RESULTS}

\section{Chronology Statistics}

The chronology statistics are shown in Table 1. The mean ring width ranged between 0.75 and $1.56 \mathrm{~mm}$. Mean sensitivity (MS), which indicates the relative difference between adjacent rings, was 0.24 , reflecting that tree growth was sensitive to the changes of the local environment. The standard deviation (SD) value was 0.26 . The first-order autocorrelation among the tree-ring series was 0.60 , indicating that tree growth in the current year had a strong influence on growth in the next year (Fritts, 1976). The value of inter-series correlation was 0.60 , with a signal-to-noise ratio of 27.60, suggesting that the chronologies recorded adequate environmental signals. The variance in the first eigenvector accounted for $42.0 \%$ in the standard chronology. An expressed population signal (EPS) threshold value of 0.85 was used to assess the most credible period of the chronology to ensure the reliability and validity of the reconstruction. The threshold corresponded to a sample depth of three trees and allowed for the reconstruction of the period of 1880-2014.

\section{The relationship between climate and tree-ring width}

The results of correlation between the MG chronology (STD) and the climatic data revealed that tree-ring width indices were negatively correlated to monthly mean temperatures in almost all months (Fig. 2); the correlations were significant in July of the prior year as well as March and from June to July of the current year $(\mathrm{P}<0.05)$, with the highest correlation coefficient in July of the current year $(\mathrm{r}=-0.46, \mathrm{P}<0.05)$ (Fig. 2). Meanwhile, Fig. 2 show there were significant positive correlations between tree-ring index and the June $\mathrm{T}_{\min }$ of the previous year. In addition, Larix gmelinii radial growth in Mangui was positively correlated with precipitation during current June to July, with significant correlation observed in July (Fig. 2). After examining different combinations of

Table 1. Statistical features of STD chronology.

\begin{tabular}{lc}
\hline Statistic & STD \\
\hline Mean sensitivity & 0.23 \\
\hline Standard deviation & 0.26 \\
\hline First order autocorrelation & 0.60 \\
\hline Mean correlation within trees & 0.60 \\
\hline Variance in first eigenvector (\%) & 42.0 \\
\hline Signal-to-noise ratio (SNR) & 27.6 \\
\hline Mean ring width (mm) & 1.16 \\
\hline Expressed population signal (EPS) & 0.91 \\
\hline First year where SSS $>0.85$ (number of trees) & $1880(3)$ \\
\hline
\end{tabular}

months, the best correlation was confirmed between the ring-width indices and monthly mean temperature from current year June to July. Therefore, we reconstructed monthly mean temperature from June to July of the current year by using the MG chronology.

\section{Development of the regression model}

Based on the results of correlation analysis, a linear regression model was used in our study to describe the connection between the tree-ring width and the June-July temperatures. The model was designed as follows:

$\mathrm{T}_{\text {mean } 6-7}=19.14-4.03 \times \mathrm{Xt}$

$\left(\mathrm{N}=55, \mathrm{R}^{2}=0.436, \mathrm{R}^{2} \mathrm{adj}=0.426, \mathrm{~F}=35.29, \mathrm{p}<0.0001\right)$

where $T_{\text {mean } 6-7}$ is the mean temperature from June to July of the current year and $\mathrm{Xt}$ is the ring-width index of the MG chronology at the $t$ year.

For the calibration period (1959-2014), the reconstruction accounted for $43.6 \%$ of the actual $\mathrm{T}_{\text {mean6-7 }}$ (Fig. 3 ), after adjusting for the loss of degrees of freedom, it still explained $42.6 \%$ of the total temperature variance. The method of split-sample was employed to check the stability and reliability of the regression model (1) (Liu et al., 2009). Statistics of calibration and verification were shown in Table 3. All calibration and verification parameters were statistically significant $(\mathrm{p}<0.05)$, which indicated that the reconstructed equation was acceptable (Fritts, 1976). In addition, the positive CE and RE values (Table 2) revealed that model (1) was stable and suitable for further temperature reconstruction (Cook et al., 1999). Significant results of PMT and ST showed a good agreement between the reconstructed and actual data. These analyses suggested that the regression model was valid for temperature reconstruction.

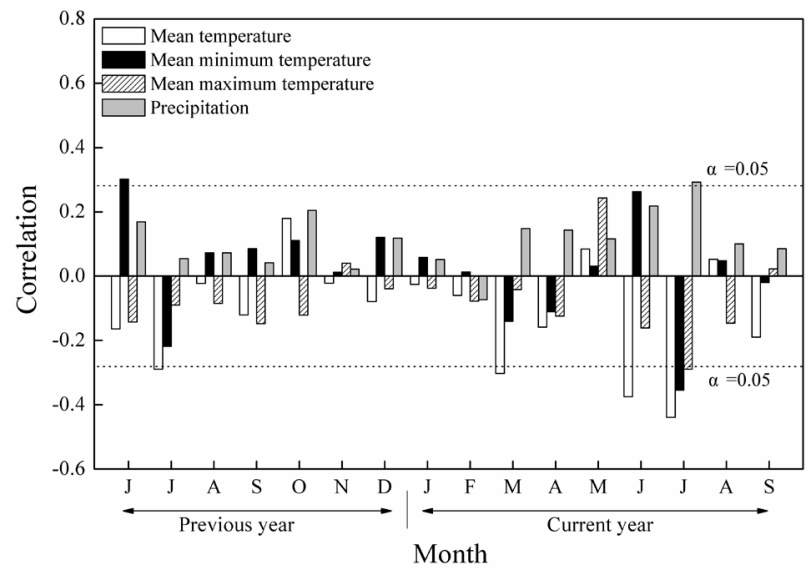

Fig. 2. Correlation coefficients between the monthly climate variables and tree-ring indices for 1959-2014. 
Table 2. Statistics of calibration and verification test for the common period of 1959-2014.

\begin{tabular}{|c|c|c|c|c|c|c|c|c|}
\hline Calibration & $\mathbf{R}$ & $\mathbf{R}^{2}$ & Verification & $\mathbf{R}$ & $\begin{array}{c}\text { Reduction } \\
\text { of error }\end{array}$ & $\begin{array}{c}\text { Coefficient of } \\
\text { efficiency }\end{array}$ & Sign test & $\begin{array}{c}\text { Product } \\
\text { means test }\end{array}$ \\
\hline Whole section 1959-2014 & $0.66^{a}$ & $0.436^{a}$ & & & & & & \\
\hline Front section 1959-1983 & $0.53^{a}$ & $0.28^{a}$ & Back section 1984-2014 & $0.71^{\mathrm{a}}$ & $0.61^{\mathrm{a}}$ & $0.35^{\mathrm{a}}$ & $(26+/ 5-)^{a}$ & $2.8^{\mathrm{a}}$ \\
\hline Back section 1984-2014 & $0.71^{a}$ & $0.50^{a}$ & Front section 1959-1984 & $0.53^{a}$ & $0.61^{a}$ & $0.43^{a}$ & $(21+/ 5-)^{a}$ & $3.3^{\mathrm{a}}$ \\
\hline
\end{tabular}

a Significant at the 0.05 level

Table 3. Rank of years of warm/cold reconstructed mean temperature from June to July ( $T_{\text {mean6-7). }}$

\begin{tabular}{lcccc}
\hline Rank & Warm year & $\begin{array}{c}T_{\max 6-7} \\
\text { RECHT89 } \\
\left({ }^{\circ} \mathbf{C}\right)\end{array}$ & Cold year & $T_{\text {max6-7 }}$ \\
\hline $\mathbf{1}$ & 2008 & 17.28 & 1888 & 12.66 \\
\hline $\mathbf{2}$ & 2003 & 16.85 & 1893 & 13.21 \\
\hline $\mathbf{3}$ & 2012 & 16.67 & 1902 & 13.22 \\
\hline $\mathbf{4}$ & 1994 & 16.65 & 1932 & 13.33 \\
\hline $\mathbf{5}$ & 2014 & 16.59 & 1898 & 13.42 \\
\hline $\mathbf{6}$ & 1954 & 16.46 & 1880 & 13.60 \\
\hline $\mathbf{7}$ & 2011 & 16.43 & 1991 & 13.62 \\
\hline $\mathbf{8}$ & 2004 & 16.38 & 1934 & 13.72 \\
\hline $\mathbf{1 0}$ & 1886 & 16.36 & 1882 & 13.73 \\
\hline $\mathbf{1 1}$ & 1885 & 16.28 & 1892 & 13.81 \\
\hline $\mathbf{1 2}$ & 1975 & 16.26 & 1978 & 13.91 \\
\hline $\mathbf{1 3}$ & 1967 & 16.15 & 1891 & 13.94 \\
\hline $\mathbf{1 4}$ & 1919 & 16.14 & 1895 & 14.04 \\
\hline $\mathbf{1 5}$ & 1883 & 16.13 & 1958 & 14.05 \\
\hline $\mathbf{1 6}$ & 2001 & 16.11 & 1890 & 14.05 \\
\hline $\mathbf{1 7}$ & 2005 & 16.09 & 1927 & 14.10 \\
\hline
\end{tabular}

\section{Temperature variations from AD 1880 to 2014}

Based on model (1), the mean temperature that was reconstructed from 1880 to 2014 for the MG region exhibited a mean of $15.1^{\circ} \mathrm{C}$ and a standard deviation of $\sigma=0.88^{\circ} \mathrm{C}$. We defined years with values $>$ mean $+1 \sigma$ as a warm year, and values $<$ mean $-1 \sigma$ as a cold year. During the last 134 years, there were 17 warm years, 17 cold years, which accounted for $12.7 \%$ of the total reconstruction years, respectively (Table 3 ). The decadal variability was highlighted by using an 11-year moving average to the reconstruction (Fig. 4B). The warm periods and cold periods can be distinguished. Cold periods occurred in $1887-1898$ (average value is $14.2^{\circ} \mathrm{C}$ ), while warm periods occurred in 1994-2014 $\left(15.9^{\circ} \mathrm{C}\right)$ (Fig. 4B). Furthermore, there are two obvious processes of mean temperature increasing in $1888-1910$ (from 14.1 to $15.5^{\circ} \mathrm{C}$, and lasting for 23 years), $1987-2012$ (from 15.1 to $16.2^{\circ} \mathrm{C}$, and lasting for 26 years).

\section{DISCUSSION}

\section{Tree growth-climate responses}

In this study, summer (June to July) temperatures were the most significant negative correlations with the

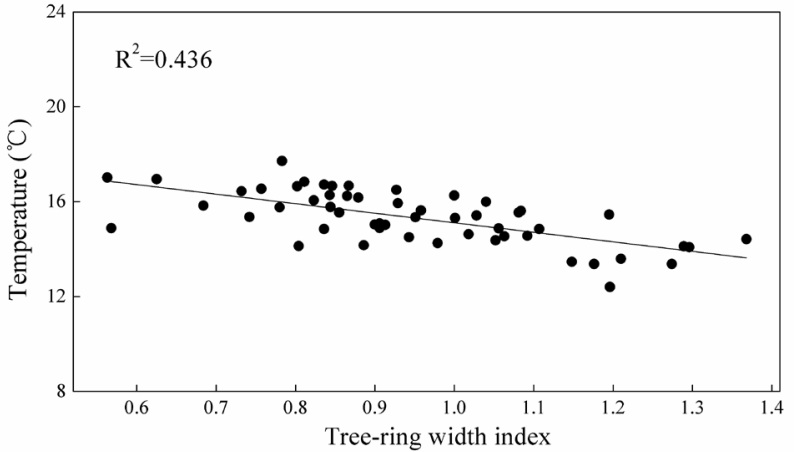

Fig. 3. Scatter plot of the tree-ring width index and the averaged Tmean6-7 from June to July (1959-2014).
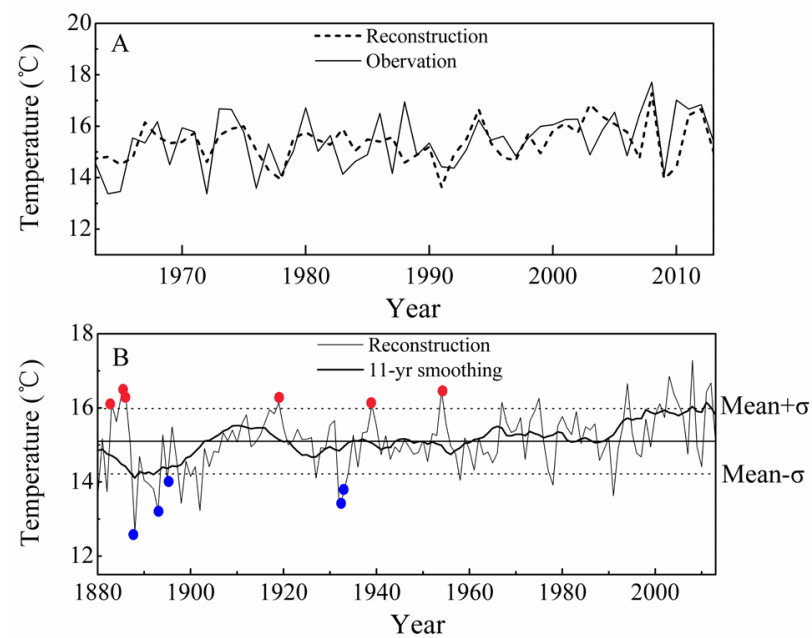

Fig. 4. (A) Comparison of actual and reconstructed $T_{\text {mean6-7 }}$ from 1959 to 2014 and $(B)$ the reconstructed June-July temperature series since 1880. The smoothed line indicates the 11-year moving average, and red dots represent drought events, blue dots represent flood events.

annual radial growth of Larix gmelinii at MG region (Fig. 2). Similar results were also obtained by studies of other tree species in various areas of China (Bao et al., 2012; Gao et al., 2013; Lu et al., 2016; Shi et al., 2013; Tian et al., 2009). The hot summer temperatures might limit the growth of Larix gmelinii due to the increased water deficits caused by the enhanced forest respiration and evaporation of soil moisture (Huang et al., 2010; Zhang et al., 2010). According to the climatic data of the study area from 1959 to 2014, the mean temperature from June to 
July was significantly negatively correlated with the average precipitation $(\mathrm{r}=-0.68, \mathrm{P}<0.001)$, indicating that the effect of precipitation on the growth of Larix gmelinii trees in the high-temperature season was significant. In this study area, soil water is mainly used by trees during the period from June to August, especially in July when the temperature is highest in a year (Bai et al., 2011). The highest precipitation occurs in July-August, but the maximum temperature occurs from June-July (Fig. 5). During this period, the increase in water demand due to transpiration may result in a deficit of soil moisture. Soil moisture evaporation was greater than precipitation, and therefore moisture requirements for growth cannot be met. Our results also revealed that the influence of mean temperatures was more significant than the influence of precipitation during the current June-July. In addition, low temperatures in previous and current June had a great limitation on tree-ring formation. The higher the $T_{\min }$ in June, the earlier the growth begins, and the longer the growing season, resulting in a wider annual ring (Wu and Shao, 1996). The radial growth of tree rings

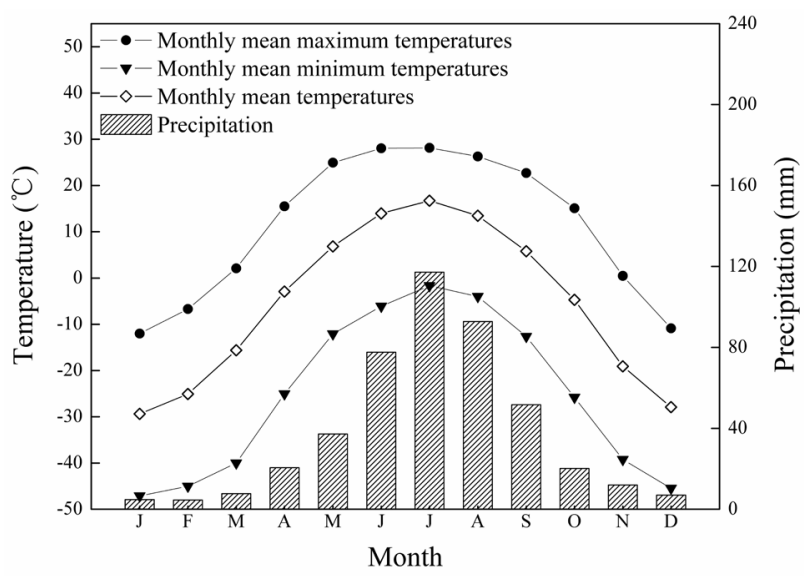

Fig. 5. Mean monthly temperature (in ${ }^{\circ} \mathrm{C}$ ) and total precipitation (in $\mathrm{mm}$ ) at Mangui (MG) in the northern Daxing'an Mountains (AD 1959-2014) based on interpolated values from 164 climate stations. is affected by the amount of stored compounds. The higher $T_{\min }$ in June of the previous year may enhance photosynthetic production and store more carbohydrates for the next summer (DeLucia and Smith, 1987). Our results are in line with those of Wang et al., 2005, who suggested that the annual growth of Larix gmelinii trees in Mohe was positively correlated with the $T_{\min }$ in June, indicating that trees respond to climate with regional homogeneity.

\section{Regional- to large-scale comparison}

Drought is not only due to lower precipitation but also to higher temperatures. Under normal rainfall conditions, high temperatures can cause severe droughts, and precipitation is accompanied by low temperatures ( $\mathrm{Yi}$ et al., 2012; Bao et al., 2012). Historical literature evidence shows that many drought and flooding events occurred in Heilongjiang Province after AD 1880 (Wen and Sun, 2007). The high-temperature years that occurred in AD $1883,1885,1886,1919,1939$, and 1954 were linked with drought events (Table 4) and low-temperature years of $1888,1892,1895,1932$ and 1934 were associated with the wet events in the study region (Table 4).

To further evaluate the reliability of this reconstruction, we compared the reconstructed series with nearby tree-ring-based reconstruction temperature series by Zhang et al., 2013 (the site codes NGHM, $680 \mathrm{~m}$ a. s. 1., $52^{\circ} 55^{\prime} \mathrm{N}, 121^{\circ} 06^{\prime} \mathrm{E} ; 193 \mathrm{~km}$ from our sampling point), Zhang et al., (2011) (the site codes IM, $51^{\circ} 03^{\prime} 15^{\prime \prime}-52^{\circ} 08^{\prime} 08^{\prime \prime} \mathrm{N}, 120^{\circ} 00^{\prime} 20^{\prime \prime}-121^{\circ} 19^{\prime} 21^{\prime \prime} \mathrm{E}$; $120 \mathrm{~km}$ from our sampling point) and reconstruction Palmer drought severity index (PDSI) series by Shi et al., 2015 (the site codes HLBE, 515-669 m a. s. 1., 49 $12^{\prime}$ N, $119^{\circ} 42^{\prime}$ E; $607 \mathrm{~km}$ from our sampling point) (Fig. 1, Fig. 6). A significant negative correlation $(\mathrm{r}=-0.43$, $\mathrm{p}<0.001$ ) between our reconstruction and the May-July PDSI reconstruction in HLBE (Fig. 6d) was found, while our reconstruction of $\mathrm{T}_{\text {mean6-7 }}$ had similar variations in the May-October temperature reconstruction in NGHM $(\mathrm{r}=0.35, \mathrm{p}<0.01$; Fig. $6 \mathrm{c})$ and May-September tempera-

Table 4. The dry/wet years of the reconstructed temperature for the Mangui (MG) region in comparison with historical documents (Wen and Sun, 2007).

\begin{tabular}{|c|c|}
\hline $\begin{array}{l}\text { Dry and } \\
\text { wet year }\end{array}$ & \\
\hline 1883 & Heilongjiang: Severe drought occurred in 27 regions in summer, such as Qiqihar, Haerbin, Moergen (now Nenjiang), Maoxing, Ningguta, etc. \\
\hline 1885 & Heilongjiang: Drought occurred in summer, such as Heilongjiang city, Moergen (now Nenjiang), Qiqihar, Sanxing (now Yilan), Ningguta, etc. \\
\hline 1886 & Heilongjiang: Drought occurred in summer, such as Heilongjiang City, Qiqihar, Moergen (now Nenjiang), Maoxing, Ningguta, etc. \\
\hline 1919 & Heilongjiang: Drought occurred in summer, such as Haerbin, Tonghe, Qiqihar, Xibuteha (now Zhalantun), Nehe, Anda, Zhaozhou, etc. \\
\hline 1939 & Heilongjiang: Severe drought occurred in Jiamusi in summer. \\
\hline 1954 & Heilongjiang: Drought occurred in summer, such as, Nenjiang, Shangzhi, Tieli, Suiling, Hailun, Nenjiang, etc. \\
\hline 1888 & Heilongjiang: Flooding disaster occurred in 27 regions in summer, such as Qiqihar, Moergen (now Nenjiang), Maoxing, etc. \\
\hline 1892 & Heilongjiang: Flooding disaster occurred in 20 regions in summer, such as Qiqihar, Maoxing, Wuchang, etc. \\
\hline 1895 & Heilongjiang: Flooding disaster occurred in summer, such as Heilongjiang City, Hulan, Boduna, Haerbin, etc. \\
\hline 1932 & Heilongjiang: Severe flooding disaster occurred in summer, such as Zhanlantun, Qiqihar, Haerbin, Tahe, Zhaodong, Dongning, etc. \\
\hline 1934 & Heilongjiang: Flooding disaster occurred in summer, such as Anda, Qiqihar, Haerbin, Nenjiang, Hulan, etc. \\
\hline
\end{tabular}


ture reconstruction in IM $(r=0.31, p<0.01$; Fig. 6b). The results showed that despite some differences in these reconstructions, similar temperature patterns were found during 1880-1885, 1888-1906, 1925-1933, 1943-1947, 1953-1964 and 1980-2008 in these areas, (Fig. 6), indicating regional climate change.

The results showed that the large-scale regional temperature variations had been well captured by our reconstruction, which was significantly positively correlated with regional gridded temperatures (Fig. 7). The above results showed that our reconstruction could capture the temperature signals well. Thus, the reconstruction preserved valid information about regional climate change and provided a valuable profile of past climatic variation in this region.

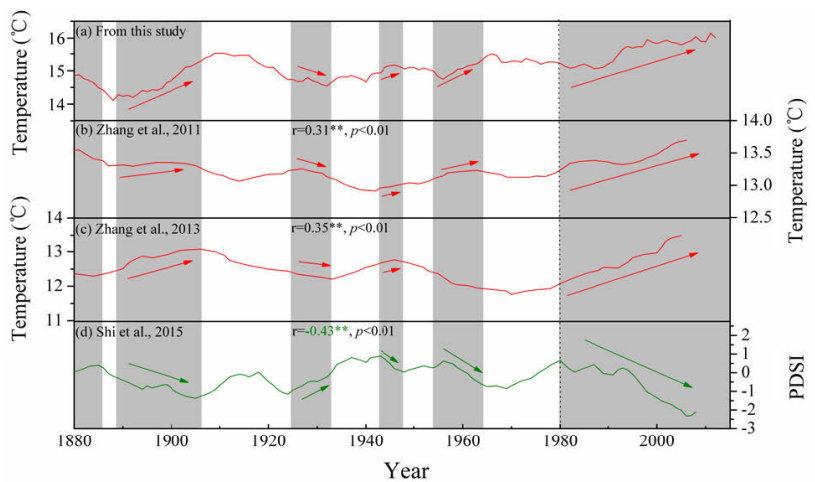

Fig. 6. Comparison of June-July mean temperature reconstruction in $M G$ with other tree-ring proxies from surrounding areas: (a) June-July maximum temperature reconstruction in this study; (b) MaySeptember temperature reconstruction in Inner Mongolia (Zhang et al., 2011); (c) May-October temperature reconstruction in northern Greater Higgnan Mountains, China (Zhang et al., 2013); (d) Annual PDSI reconstruction from tree-ring of Mongolian pine in Hulunbuir, Northeast China (Shi et al., 2015). The gray areas mean the common warm/cold periods.

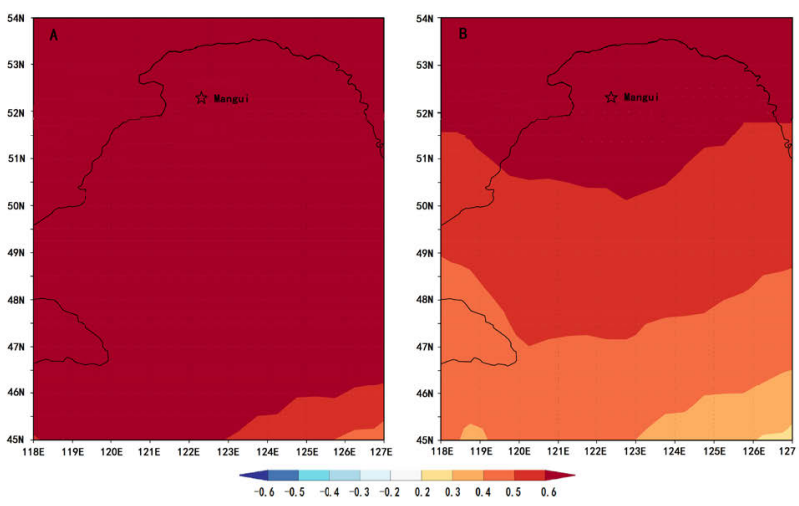

Fig. 7. Spatial correlation of $(A)$ instrumental and $(B)$ reconstructed June-July temperatures with regional gridded June-July temperatures during the period 1959-2014. The asterisk mark in is the sampling position.

\section{Possible forcing mechanism}

The multi-taper method (MTM) of spectral analysis (Wei, 2010) revealed that the reconstructed $\mathrm{T}_{\text {mean6-7 }}$ exhibited significant cycles, which indicated that the $\mathrm{T}_{\text {mean6- }}$ in MG region could be affected by other factors. Significant peaks of 2.5, and 2.2 years were observed (Fig. 8). The 2-7 years peak cycle was found in some temperaturerelated reconstruction by tree-rings in the northeast of China (Bao et al., 2012; Liu et al., 2013), which were within the range of the ENSO cycle (Allan et al., 1996; $\mathrm{Su}$ and Wang, 2007; Hocke, 2009; Gergis and Fowler, 2009). A possible connection between $T_{\text {mean6-7 }}$ variability and the ENSO was supported by the significantly positive correlations between the reconstructed $\mathrm{T}_{\text {mean6-7 }}$ and sea surface temperatures (SSTs) in the eastern equatorial Pacific Ocean (Fig. 9). Some studies have suggested that ENSO had a strong influence on the strength of East Asian Summer Monsoon (EAWM) (Zhang et al., 1999; $\mathrm{Wu}$ and Wang, 2002; Lu, 2005). Mangui is located at the boundary zone of the East Asia Summer Monsoon (EASM) (Yang, et al., 1992; Li and Zeng, 2003). The East Asia Summer Monsoon climate regimes dominate the fecundity or deficit of water availability, and trends in temperature (Zhu et al., 2009; Li et al., 2009; Chen et al., 2011, 2012; Gao et al., 2013), the annual warm summers are related to weaker summer East Asia monsoon climate (Zhu et al., 2009; Li et al., 2009). In other words, the stronger the monsoon is, the lower the summer temperature is, and vice versa. The cycles of 10.9-years may suggest the impact of solar effects, such as sunspot activity (Stuiver and Braziunas, 1993; Grootes and Stuiver, 1997; Yi et al., 2012), which was supported by the significant positive correlations of the reconstructed $T_{\text {mean6-7 }}$ with the number of sunspots (http://www.sidc.be/silso/datafiles) from June to July of the current year, with a correlation coefficient of 0.215 $(\mathrm{N}=135,1880-2014, \mathrm{p}=0.009)$.

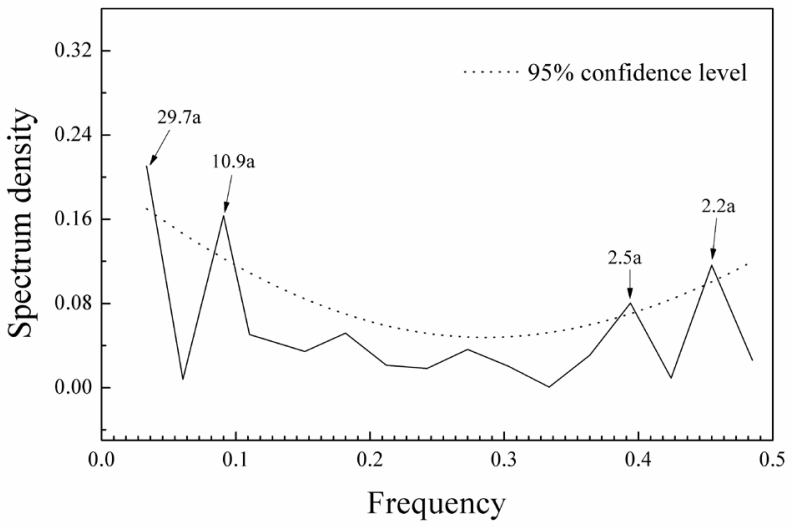

Fig. 8. The power spectrum analyses of reconstructed June-July mean temperature. 


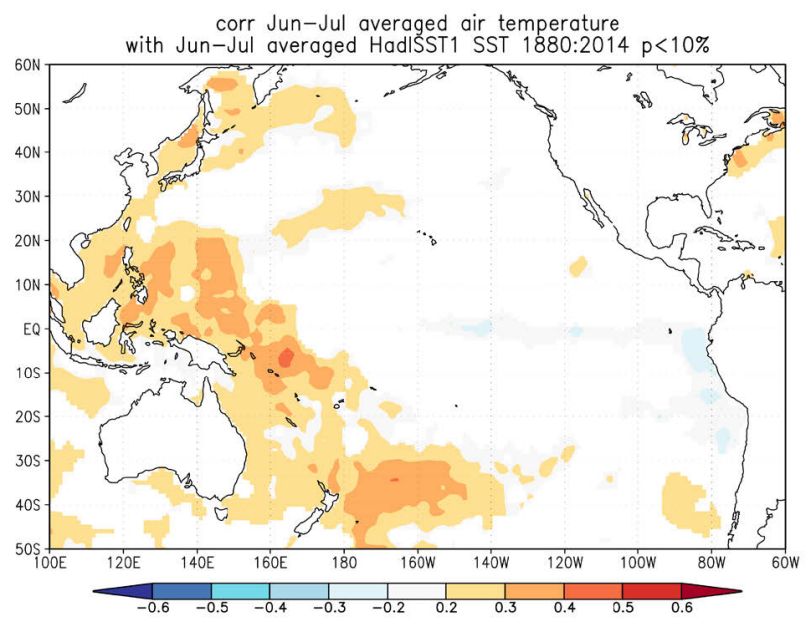

Fig. 9. Spatial correlation for the reconstruction with June-July averaged HadISST1 SST during the period of 1880-2014.

The significant spectral peaks at 29.7-yr (Fig. 8) was possibly linked with the 15-30 yr periods of the Pacific Decadal Oscillation (PDO) (Minobe, 1999; Gedalof et al., 2002; Ma, 2007), which was supported by the significant positive correlations of the reconstructed $\mathrm{T}_{\text {mean6-7 }}$ with SSTs in the western Pacific Ocean (Fig. 9) and with the annual PDO (MacDonald and Case 2005), with $\mathrm{R}^{2}=$ $0.156(\mathrm{~N}=117, \mathrm{p}<0.05 ; 1880-1996)$. Some other treering studies closed to our study region, discovered that the Hailar pine, Larix gmelinii and tree-ring widths are also significantly correlated with the PDO (Chen et al., 2011, 2012; Bao et al., 2015).

As mentioned above, the complex connections with the ENSO, PDO and Solar activity suggested that the temperature in the Mangui area indicated both localregional climate signals and global-scale climate changes.

\section{CONCLUSION}

The mean temperature from June to July was reconstructed for the period of 1880 to 2014 by using tree-ring data from MG in the northern Daxing'an Mountains, China. The reconstructed temperature series provided essential information concerning temperature variations in this region. During the last 134 years, there were 17 warm years, 17 cold years, which accounted for $12.7 \%$ of the total reconstruction years, respectively. Cold episodes occurred in the intervals 1887-1898, while warm episodes occurred in 1994-2014. In and near the study region, the warmer events coincided with dry periods and the colder events consistent with wet conditions. The spatial correlation analyses between the reconstruction series and gridded temperature data revealed that the regional climatic variations were well captured by this study and the reconstruction represented a regional temperature signal for the northern Daxing'an Mountains. In addition, multi-taper method spectral analysis revealed the existence of significant periodicities in our reconstruction. Significant spectral peaks were found at 29.7, $10.9,2.5$, and 2.2 years. The significant spatial correlations between our temperature reconstruction and the El Niño-Southern Oscillation (ENSO), and Pacific Decadal Oscillation (PDO) and Solar activity suggested that temperature variability in the Mangui area was probably driven by extensive large-scale atmospheric-oceanic variability and solar activity.

\section{ACKNOWLEDGEMENTS}

The research was funded by the National Natural Science Foundation of China (Nos. 41330530, 41430639 and 41575153).

\section{REFERENCES}

Allan R, Lindesay J and Parker D, 1996. El Nino: Southern Oscillation and Climatic Variability. Commonwealth CSIRO Publishing, Melbourne, Australia.

Bai, XF, H Han, FY Zhou, RS Zhang, GJ Zhao and JH Liu, 2011. Study on ecological characteristics of transpiration and water consumption of Pinus sylvestris var. mongolica in sand. Journal of Liaoning Technical University (Natural Science) 30(3): 404-407. (In Chinese with English abstract).

Bao G, Liu Y and Linderholm HW, 2012. April-September mean maximum temperature inferred from Hailar pine (Pinus sylvestris var. mongolica) tree rings in the Hulunbuir region, Inner Mongolia, back to 1868 AD. Palaeogeography, Palaeoclimatology, Palaeoecology 313(1): 162-172, DOI 10.1016/j.palaeo.2011.10.017.

Bao G, Liu Y and Liu N, 2015. Drought variability in eastern Mongolian Plateau and its linkages to the large-scale climate forcing. Climate Dynamics 44(3-4): 717-733, DOI 10.1007/s00382-0142273-7.

Biondi F and Waikul K, 2004. DENDROCLIM2002: A C++ program for statistical calibration of climate signals in tree-ring chronologies. Computers and Geosciences 30(3): 303-311, DOI 10.1016/j.cageo.2003.11.004.

Blasing TJ, Solomon AM and Duvick DN, 1984. Response functions revisited. Tree-Ring Bulletin 44: 1-15.

Bond G, Kromer B, Beer J, Muscheler R, Evans MN, Showers W, Hoffmann S, Lotti-Bond R, Hajdas I and Bonani G, 2001. Persistent Solar Influence on North Atlantic Climate During the Holocene. Science 294: 2130-2136, DOI 10.1126/science.1065680.

Cao M and Woodward FI, 1998. Dynamic responses of terrestrial ecosystem carbon cycling to global climate change. Nature 393(6682): 249-252, DOI 10.1038/30460.

Chen Z, He X and Cook ER, 2011. Detecting dryness and wetness signals from tree-rings in Shenyang, Northeast China. Palaeogeography, Palaeoclimatology, Palaeoecology 302(3): 301-310, DOI 10.1016/j.palaeo.2011.01.018.

Chen Z, Zhang X and Cui M, 2012. Tree-ring based precipitation reconstruction for the forest-steppe ecotone in northern Inner Mongolia, China and its linkages to the Pacific Ocean variability. Global and Planetary Change 86-87(4): 45-56, DOI 10.1016/j.gloplacha.2012.01.009.

Cook ER, 1990. Methods of Dendrochronology: Applications in Environmental Science.

Cook ER, 1985. A time series approach to tree-ring standardization. $\mathrm{Ph} . \mathrm{D}$. Thesis, University of Arizona, Tucson, AZ, USA

Cook ER and Briffa KR, 1990. Data analysis. In Methods of Dendrochronology; Cook, E.R., Kairiukstis, L.A., Eds.; Kluwer: Boston, MA, USA pp. 97-162

Cook ER, Anchukaitis KJ and Buckley BM, 2010. Asian monsoon failure and megadrought during the last millennium. Science 328(5977): 486-489, DOI 10.1126/science.1185188. 
Cook ER, Meko DM, Stahle DW and Cleaveland MK, 1999. Drought reconstructions for the continental United States. Journal of Climate 12: 1145-1162, DOI 10.1175/15200442(1999)012<1145:DRFTCU>2.0.CO;2.

Davi N, Jacoby G and Fang K, 2010. Reconstructing drought variability for Mongolia based on a large scale tree ring network: 1520-1993. Journal of Geophysical Research Atmospheres 115(D22): 18421851, DOI 10.1029/2010JD013907.

DeLucia EH and Smith WK, 1987. Air and soil temperature limitations on photosynthesis in Engelmann spruce during summer. Canadian Journal of Forest Research 17: 527-533, DOI 10.1139/x87-088.

Ding YH and Dai XS, 1994. Temperature variation in China during the last 100 years. Meteorology 12: 19-26 (in Chinese).

Esper J, Cook ER and Schweingruber FH, 2002. Low-frequency signals in long tree-ring chronologies for reconstructing past temperature variability. Science 295: 2250-2253, DOI 10.1126/science. 1066208.

Fritts HC, 1976. Tree Rings and Climate. Academic Press: New York, NY, USA

Holmes RL, 1983. Computer-Assisted Quality Control in Tree-Ring Dating and Measurement. Tree-Ring Bulletin 44(3): 69-75.

Gao J, Shi Z and Xu L, 2013. Precipitation variability in Hulunbuir, northeastern China since 1829 AD reconstructed from tree-rings and its linkage with remote oceans. Journal of Arid Environments 95(8): 14-21, DOI 10.1016/j.jaridenv.2013.02.011.

Gedalof Z, Mantua NJ and Peterson DL, 2002. A multi-century perspective of variability in the Pacific Decadal Oscillation: new insights from tree rings and coral. Geophysical Research Letters 29(24): 57-51, DOI 10.1029/2002GL015824.

Gergis JL and Fowler AM, 2009. A history of ENSO events since A.D. 1525: implications for future climate change. Climatic Change 92(3-4): 343-387, DOI 10.1007/s10584-008-9476-z.

Grootes PM and Stuiver M, 1997. Oxygen 18/16 variability in Greenland snow and ice with 103 to 105 -year time resolution. Journal of Geophysical Research 102: 26455-26470, DOI 10.1029/97JC00880

Herrera VMV, Mendoza B and Herrera GV, 2015. Reconstruction and prediction of the total solar irradiance: From the Medieval Warm Period to the 21st century. New Astronomy 34: 221-233, DOI 10.1016/j.newast.2014.07.009.

Hocke K, 2009. QBO in solar wind speed and its relation to ENSO. Journal of Atmospheric and Solar-Terrestrial Physics 71(2): 216220, DOI 10.1016/j.jastp.2008.11.017.

Huang C, Zheng X and Tait A, 2013. On using smoothing spline and residual correction to fuse rain gauge observations and remote sensing data. Journal of Hydrology 508(2): 410-417, DOI 10.1016/j.jhydrol.2013.11.022.

Huang J, Tardif JC and Bergeron Y, 2010. Radial growth response of four dominant boreal tree species to climate along a latitudinal gradient in the eastern Canadian boreal forest. Global Change Biology 16(2): 711-731, DOI 10.1111/j.1365-2486.2009.01990.x.

IPCC (Intergovernmental Panel on Climate Change), 2014. Climate change 2014: mitigation of climate change [M/OL]. Cambridge: Cambridge University Press, 2014 [2014-09-10]. http:// www.ipcc.ch/report/ar5/wg3

Kittel TGF, Steffen WL and Chapin FSI, 2000. Global and regional modelling of Arctic-boreal vegetation distribution and its sensitivity to altered forcing. Global Change Biology 6(S1): 1-18, DOI 10.1046/j.1365-2486.2000.06011.x.

Lean J and Rind D, 1999. Evaluating sun-climate relationships since the Little Ice Age. Journal of atmospheric and solar-terrestrial physics 61(1-2): 25-36, DOI 10.1016/S1364-6826(98)00113-8.

Li J and Zeng Q, 2003. A new monsoon index and the geographical distribution of the global monsoons. Advances in Atmospheric Sciences 20(2): 299-302.

Li J, Cook ER and D'Arrigo R, 2009. Moisture variability across China and Mongolia: 1951-2005. Climate Dynamics 32(7-8): 11731186, DOI 10.1007/s00382-008-0436-0.

Li J and Gong Q, 2006. Analysis of Temperature Change Characteristics in Summer in Northeast China. Journal of Meteorology and Environment 1: 6-10.
Li T, Zheng X, Dai Y, Yang C, Chen Z, Zhang S and Liao R, 2014 Mapping near-surface air temperature, pressure, relative humidity and wind speed over Mainland China with high spatiotemporal resolution. Advances In Atmospheric Sciences 31: 1127-1135, DOI 10.1007/s00376-014-3190-8.

Liu Y, Bao G and Song H, 2009. Precipitation reconstruction from Hailar pine (Pinus sylvestris var. mongolica) tree rings in the Hailar region, Inner Mongolia, China back to 1865 AD. Palaeogeography, Palaeoclimatology, Palaeoecology 282(4): 81-87, DOI 10.1016/j.palaeo.2009.08.012.

Liu Y, Wang Y and Li Q, 2013. Reconstructed May-July mean maximum temperature since $1745 \mathrm{AD}$ based on tree-ring width of Pinus tabulaeformis, in Qianshan Mountain, China. Palaeogeography Palaeoclimatology Palaeoecology 388(19): 145-152, DOI 10.1016/j.palaeo.2013.08.011.

$\mathrm{Lu} \mathrm{RY,} \mathrm{2005.} \mathrm{Interannual} \mathrm{variation} \mathrm{of} \mathrm{North} \mathrm{China} \mathrm{rainfall} \mathrm{in} \mathrm{rainy}$ season and SSTs in the equatorial eastern Pacific. Chinese Science Bulletin 50: 2069-2073, DOI 10.1360/04wd0271.

$\mathrm{Lu} \mathrm{R}$, Jia F and Gao S, 2016. Tree-ring reconstruction of JanuaryMarch minimum temperatures since 1804 on Hasi Mountain, northwestern China. Journal of Arid Environments 127: 66-73, DOI 10.1016/j.jaridenv.2015.10.020.

Ma ZG, 2007. The interdecadal trend and shift of dry/wet over the central part of north China and their relationship to the Pacific Decadal Oscillation (PDO). Chinese Science Bulletin 52 (12): 2130 2139, DOI 10.1007/s11434-007-0284-z.

MacDonald GM and Case RA, 2005. Variations in the Pacific Decadal Oscillation over the past millennium. Geophysical Research Letters 32: L08703, DOI 10.1029/2005GL022478.

Malik I, Tie Y, Owczarek P, Wistuba M, Pilorz W, Woskowicz-Ślęzak B, 2013. Human-planted alder trees as a protection against debris Human-planted alder trees as a protection against debris flows (a dendrochronological study from the Moxi Basin, Southwestern China). Geochronometria 40(3): 208-216, DOI 10.2478/s13386013-0113-x.

Malik I, Wistuba M, Tie Y, Owczarek P, Woskowicz-Ślęzak B and Łuszczyńska K, 2017. Mass movements of differing magnitude and frequency in a developing high-mountain area of the Moxi basin, Hengduan Mts, China - A hazard assessment. Applied Geography 87: 54-65, DOI 10.1016/j.apgeog.2017.08.003.

Mann ME, Zhang Z and Rutherford S, 2009. Global signatures and dynamical origins of the Little Ice Age and Medieval Climate Anomaly. Science 326(5957): 1256-1260, DOI 10.1126/science.1177303.

Minobe S, 1999. Resonance in bidecadal and pentadecadal climate oscillations over the North Pacific: Role in climatic regime shifts. Geophysical Research Letters 26(7): 855-858, DOI 10.1029/1999GL900119.

Moberg A, Sonechkin DM and Holmgren K, 2005. Highly variable Northern Hemisphere temperatures reconstructed from low- and high-resolution proxy data. Nature 433(7026): 613-617, DOI 10.1038 /nature 03265 .

PAGES 2 K Consortium, 2013. Continental-scale temperature variability during the past two millennia. Nature Geoscience 6: 339-346, DOI 10.1038/NGEO1797.

Panthi S, Bräuning A, Zhou ZK and Fan ZX, 2017. Tree rings reveal recent intensified spring drought in the central Himalaya, Nepal. Global and Planetary Change 157: 26-34, DOI 10.1016/j.gloplacha.2017.08.012.

Pederson N, Jacoby GC and D'Arrigo RD, 2001. Hydrometeorological Reconstructions for Northeastern Mongolia Derived from Tree Rings: 1651-1995. Journal of Climate 14(5): 872-881, DOI 10.1175/1520-0442(2001)014<0872:HRFNMD>2.0.CO;2.

Shao X, Xu Y, Yin ZY, 2010. Climatic implications of a 3585-year treering width chronology from the northeastern Qinghai-Tibetan Plateau. Quaternary Science Reviews 29(17-18): 2111-2122, DOI 10.1016/j.quascirev.2010.05.005.

Shaver GR, Canadell J and lii FSC, 2000. Global warming and terrestrial ecosystems: A conceptual framework for analysis. Bioscience 50(10): $\quad 871-882, \quad$ DOI $10.1641 / 0006$ 3568(2000)050[0871:GWATEA]2.0.CO;2. 
Shi Z, Gao J and Yang X, 2013. Tree-ring based reconstruction of mean maximum temperatures since AD 1829. Forestry Chronicle 89(2): 184-191, DOI 10.5558/tfc2013-036.

Shi Z, Xu L and Dong L, 2015. Growth-climate response and drought reconstruction from tree-ring of Mongolian pine in Hulunbuir, Northeast China. Journal of Plant Ecology 9(1): 51-60, DOI 10.1093/jpe/rtv029.

Song K, Yu Q, Shang KK, Yang TH and Da LJ, 2011. The spatiotemporal pattern of historical disturbances of an evergreen broadleaved forest in East China: a dendroecological analysis. Plant Ecology 212(8): 1313-1325, DOI 10.1007/s11258-011-9907-1.

Stuiver M and Braziunas T, 1993. Modeling atmospheric ${ }^{14} \mathrm{C}$ influences and ${ }^{14} \mathrm{C}$ ages of marine samples to 10,000 BC. Radiocarbon 35: $137-189$.

Su MF and Wang HJ, 2007. Relationship and its instability of ENSOChinese variations in droughts and wet spells. Science In China Series D-Earth Sciences 50: 145-152, DOI 10.1007/s11430-0072006-4.

Tian QH, Gou XH and Yong Z, 2009. May-June mean temperature reconstruction over the past 300 years based on tree rings in the Qilian Mountains of the northeastern Tibetan Plateau. Iawa Journal 30(4): 421-434, DOI 10.1163/22941932-90000229.

Wang LL, Shao XM, Huang L and Liang EY, 2005. Tree-ring characteristics of Larix gmelinii and Pinus sylvestris var. mongolica and their response to climate in Mohe, China. Acta Phytoecol Sin 29: 380-385.

Wang SW, Ye JL and Gong DY, 1998. Construction of mean annual temperature series for the last one hundred years in China. $J \mathrm{Appl}$ Meteorol Sci 9: 392-401 (in Chinese)

Wei FY, 2010. Modern Climate Statistics Diagnosis and Forecasting Techniques. China Meteorological Press, Beijing (in Chinese).

Wen KG and Sun YG, 2007. The Documents of Chinese Meteorological Disaster: Volume of Heilongiiang Province. Meteorological Publishers, Beijing (in Chinese).

Wigley TML, Briffa KR and Jones PD, 1984. On the Average Value of Correlated Time Series, with Applications in Dendroclimatology and Hydrometeorology. Journal of Climatology and Applied Meteorology 23(2): 201-213, DOI 10.1175/15200450(1984)023<0201:OTAVOC $>2.0 . C O ; 2$.

Wu R and Wang B, 2002. A Contrast of the East Asian Summer Monsoon-ENSO Relationship between 1962-77 and 1978-93. Journal of Climate 15: 3266-3279, DOI 10.1175/15200442(2002)015<3266:ACOTEA>2.0.CO;2.

Wu X and Shao X, 1996. A preliminary study on impact of climate change on tree growth using tree ring-width data. Acta Geographica Sinica 1996(S1): 92-101.

Wu X P, Zhu B and Zhao SQ, 2004. Comparison of community structure ad species diversity of mixed forests of deciduous broad- leaved tree and Korean pine in northeast China. Chinese Biodiversity 12(1): 174-181.

Yang G, Chen X and Zhou D, 1992. Ordination and gradient analysis of coniferous forest in Daxinganling. Journal of Northeast Forestry University 3(1): 42-47.

Yi L, Yu H and Ge J, 2012. Reconstructions of annual summer precipitation and temperature in north-central China since $1470 \mathrm{AD}$ based on drought/flood index and tree-ring records. Climatic Change 110(1-2): 469-498, DOI 10.1007/s10584-011-0052-6.

Yu J, Shah S, Zhou G, Xu Z and Liu Q, 2018. Tree-Ring-Recorded Drought Variability in the Northern Daxing'anling Mountains of Northeastern China. Forests 9: 674, DOI 10.3390/f9110674.

Yu S, Wang LL and Jin C, 2012. Reconstructing mean maximum temperatures of May-August from tree-ring maximum density in North Da Hinggan Mountains, China. Science Bulletin 57(16): 2007-2014, DOI 10.1007/s11434-012-5055-9.

Zhang Q, Cheng G and Yao T, 2003. A 2,326-year tree-ring record of climate variability on the northeastern Qinghai-Tibetan Plateau. Geophysical Research Letters 30(14): 1739, DOI 10.1029/2003GL017425.

Zhang RH, Sumi A and Kimoto M, 1999. A diagnostic study of the impact of El Niño on the precipitation in China. Advances In Atmospheric Sciences 16: 229-241, DOI 10.1007/BF02973084.

Zhang T, Yuan Y and Wei W, 2013. Tree-ring-based temperature reconstruction for the northern Greater Higgnan Mountains, China, since A.D. 1717. International Journal of Climatology 33(2): 422 429, DOI 10.1002/joc.3433.

Zhang XL, Cui MX and Ma YJ, 2010. Chronology of the annual ring width of Larix gmeliniii in the Kudur area of Daxing'anling and its relationship with climate change. Chinese Journal of Applied Ecology 21(10): 2501-2507(In Chinese).

Zhang X, Bai X and Chang Y, 2016. Increased sensitivity of Dahurian larch radial growth to summer temperature with the rapid warming in Northeast China. Trees 30(5): 1799-1806, DOI 10.1007/s00468-016-1413-6.

Zhang X, He X and Li J, 2011. Temperature reconstruction (17502008) from Dahurian larch tree-rings in an area subject to permafrost in Inner Mongolia, Northeast China. Climate Research 47(3): 151-159, DOI 10.3354/cr00999.

Zhang XL, Cui MX and Ma YJ, 2010. Larix gmelinii tree-ring width chronology and its responses to climate change in Kuduer, Great Xing' an Mountains. Chinese Journal of Applied Ecology 21(10): 2501

Zhu HF, Fang XQ and Shao XM, 2009. Tree ring-based February-April temperature reconstruction for Changbai Mountain in Northeast China and its implication for East Asian winter monsoon. Climate of the Past Discussions 5(2): 661-666, DOI 10.5194/cp-5-6612009. 